\title{
Successful receptor-mediated radiation therapy of xenografted human midgut carcinoid tumour
}

\author{
L Kölby ${ }^{*, 1}$, P Bernhardt ${ }^{2}$, V Johanson', A Schmitt ${ }^{2}$, H Ahlman', E Forssell-Aronsson ${ }^{2}$, H Mäcke ${ }^{3}$ and O Nilsson ${ }^{4}$ \\ 'Department of Surgery, Lundberg Laboratory for Cancer Research, Institute for Surgical Sciences, Göteborg University, Sahlgrenska University Hospital, \\ Göteborg SE-4 13 45, Sweden; ${ }^{2}$ Department of Radiation Physics, Lundberg Laboratory for Cancer Research, Göteborg University, Sahlgrenska University \\ Hospital, Göteborg, Sweden; ${ }^{3}$ Division of Radiological Chemistry, University Hospital, Basel, Switzerland; ${ }^{4}$ Departments of Pathology, Lundberg Laboratory \\ for Cancer Research, Göteborg University, Sahlgrenska University Hospital, Göteborg, Sweden
}

Somatostatin receptor (sstr)-mediated radiation therapy is a new therapeutic modality for neuroendocrine (NE) tumours. High expression of sstr in NE tumours leads to tumour-specific uptake of radiolabelled somatostatin analogues and high absorbed doses. In this study, we present the first optimised radiation therapy via sstr using [ ${ }^{177}$ Lu-DOTA $^{0}$-Tyr ${ }^{3}$ - -octreotate given to nude mice xenografted with the human midgut carcinoid GOTI. The tumours in 22 out of 23 animals given therapeutic amounts showed dosedependent, rapid complete remission. The diagnostic amount $\left(0.5 \mathrm{MBq}\left[{ }^{177} \mathrm{Lu}\right.\right.$-DOTA ${ }^{0}$-Tyr ${ }^{3}$-octreotate) did not influence tumour growth and was rapidly excreted. In contrast, the therapeutic amount (30 MBq [ ${ }^{177}$ Lu-DOTA $^{0}$-Tyr ${ }^{3}$ ]-octreotate) induced rapid tumour regression and entrapment of ${ }^{177} \mathrm{Lu}$ so that the activity concentration of ${ }^{177}$ Lu remained high, 7 and 13 days after injection. The entrapment phenomenon increased the absorbed dose to tumours from 1.6 to $4.0 \mathrm{GyMBq}^{-1}$ and the tumours in animals treated with $30 \mathrm{MBq}$ received $120 \mathrm{~Gy}$. Therapeutic amounts of [ ${ }^{177}$ Lu-DOTA ${ }^{0}-\mathrm{Tyr}^{3}$ ]-octreotate rapidly induced apoptosis and gradual development of fibrosis in grafted tumours. In conclusion, human midgut carcinoid xenografts can be cured by receptormediated radiation therapy by optimising the uptake of radioligand and taking advantage of the favourable change in biokinetics induced by entrapment of radionuclide in the tumours.

British Journal of Cancer (2005) 93, I |44- | I 5 I. doi: I0.1038/sj.bjc.6602845 www.bjcancer.com

Published online 25 October 2005

(C) 2005 Cancer Research UK

Keywords: carcinoid; GOTI; somatostatin receptors; [ ${ }^{177}$ Lu-DOTA ${ }^{0}-$ Tyr $^{3}$ ]-octreotate; therapy

\begin{abstract}
Midgut carcinoids are the most frequent neuroendocrine (NE) tumours of the gastrointestinal tract and often present with widespread disease and severe hormonal symptoms (Modlin et al, 2003). These tumours have high expression of somatostatin receptors (sstr), which can be exploited for diagnostic and therapeutic purposes (Nilsson et al, 1998). The most sensitive method to detect carcinoid metastases is sstr scintigraphy using ${ }^{111}$ In coupled with the somatostatin analogue octreotide via the chelator DTPA (Krenning et al, 1993; Ahlman et al, 1994; Cimitan et al, 2003). Pharmacological treatment of the carcinoid syndrome with long-acting somatostatin analogues reduces hormone release and related symptoms in the majority of patients. However, there is no evidence that somatostatin analogues exert antiproliferative actions on these tumours, although individual cases with induction of apoptosis have been reported (Eriksson and Öberg, 1999; Öberg, 1999; Bousquet et al, 2001). The only curative treatment for carcinoid tumours is surgical, but due to late diagnosis, radical surgery is seldom possible. Debulking procedures offer palliation of hormonal symptoms and may prolong survival (McEntee et al, 1990; Ahlman et al, 2000). Palliative treatment may include chemotherapy and biotherapy with interferon, both with limited
\end{abstract}

*Correspondence: Dr L Kölby; E-mail: lars.kolby@surgery.gu.se Received 29 June 2005; revised 19 September 2005; accepted 29 September 2005; published online 25 October 2005 benefits and adverse effects (Öberg, 1993; Moertel et al, 1994; Kölby et al, 2003). Following interventional and medical treatment, the 5-year survival is as high as $69 \%$ for patients with liver metastases (Wängberg et al, 1996; Hellman et al, 2002).

A new treatment strategy is directed radiation therapy with radiolabelled somatostatin analogues. The first therapies were attempted with $\left[{ }^{111} \mathrm{In}\right.$-DTPA $\left.{ }^{0}\right]$-octreotide and resulted in reduced tumour markers such as chromogranin A $(\mathrm{CgA}$, the general $\mathrm{NE}$ marker) and 5-hydroxy indole acetic acid (5-HIAA, the serotonin metabolite), but only occasionally objective tumour responses (Fjälling et al, 1996; McCarthy et al, 1998; Krenning et al, 1999). ${ }^{111}$ In emits mainly photons that will cause a high whole body irradiation, which limits its use for therapy (Bernhardt et al, 2001). ${ }^{111}$ In also emits Auger electrons with extremely short range with the potential to cause cell death, if the radionuclide can be allocated to the nucleus (Bernhardt et al, 2003b). Using the highenergy beta emitter ${ }^{90} \mathrm{Y}$, coupled to $\left[\mathrm{Tyr}^{3}\right]$-octreotide via the chelator DOTA $(1,4,7,10$-tetraazacyclododecane,1,4,7,10-tetraacetic acid), partial tumour remission was achieved in $7-24 \%$ of the patients (Paganelli et al, 2001; Waldherr et al, 2001; Valkema et al, 2002). Development of new somatostatin analogues with higher receptor affinity and higher degree of receptor internalisation will improve the therapeutic efficacy. The new somatostatin-based radioligand [DOTA $\left.{ }^{0}, \mathrm{Tyr}^{3}, \mathrm{Thr}^{8}\right]$-octreotide $\left(=\left[\mathrm{DOTA}^{0}, \mathrm{Tyr}^{3}\right]\right.$ octreotate) has a higher affinity for sstr2 than $\left[\mathrm{DOTA}^{0}, \mathrm{Tyr}^{3}\right]$ octreotide, and coupled with the medium-energy $\beta$-emitter ${ }^{177} \mathrm{Lu}$, 
high absorbed doses can be achieved (de Jong et al, 1997; Reubi et al, 2000; de Jong et al, 2001). ${ }^{177} \mathrm{Lu}$ has a shorter range than ${ }^{90} \mathrm{Y}$ and is therefore better suited for therapy of smaller tumours (Bernhardt et al, 2001; Bernhardt et al, 2003a). Previous experimental studies with xenografts have been performed using rat pancreatic acinar tumours carrying sstr, while the GOT1 model is an authentic human carcinoid with preserved phenotype (de Jong et al, 1998, 2001; Kölby et al, 2001). In a recent series, patients with large NE tumour burden were treated with $\left[{ }^{177} \mathrm{Lu}\right.$-DOTA ${ }^{0}$ $\mathrm{Tyr}^{3}$ ]-octreotate and partial tumour regression was seen in $35 \%$ and complete remission in 3\% (Kwekkeboom et al, 2003).

In the present study, we analysed the effect of treatment with $\left[{ }^{177} \mathrm{Lu}\right.$-DOTA $\left.{ }^{0}-\mathrm{Tyr}^{3}\right]$-octreotate of the human midgut carcinoid GOT1 xenografted to nude mice. Our aims were to optimise the uptake of $\left[{ }^{177} \mathrm{Lu}\right.$-DOTA $\left.{ }^{0}-\mathrm{Tyr}^{3}\right]$-octreotate by defining the point of receptor saturation following a single i.v. injection of the radiopharmaceutical and to evaluate the effect of sstr-mediated radiation therapy with $\left[{ }^{177} \mathrm{Lu}-\mathrm{DOTA}{ }^{0}-\mathrm{Tyr}^{3}\right]$-octreotate given to xenografted midgut carcinoid tumours.

\section{MATERIAL AND METHODS}

\section{Animal model}

The transplantable human midgut carcinoid GOT1 was established as previously described (Kölby et al, 2001). In brief, cultured GOT1 cells were inoculated subcutaneously into nude mice. After 6 months, tumours became visible. These tumours were minced into pieces and new generations of tumours were generated by transplantation of tumour tissue to the subcutis of nude mice. When the tumours were $5-10 \mathrm{~mm}$ in size, the experiments were started. The experiments were approved by the Ethical Committee for Animal Research at Göteborg University. All animal procedures were consistent with the animal use guidelines of the UKCCCR.

\section{Pharmaceuticals}

Kits of $\left[\right.$ DOTA $^{0}-$ Tyr $^{3}$ ]-octreotate were made by mixing $2.02 \mathrm{mg}$ [DOTA ${ }^{0}-$ Tyr $^{3}$ ] octreotate (synthesized by Jörg Schmitt, Division of Radiological Chemistry, University Hospital, Basel, Switzerland) with $630 \mathrm{mg}$ sodium ascorbate (VWR International AB, Sweden), $125 \mathrm{mg}$ gentisic acid (2,5-dihydroxy benzoic acid; VWR International AB, Sweden) and $5 \mathrm{ml} 0.05 \mathrm{~m} \mathrm{HCl}$. Each kit contained $40 \mu \mathrm{g}$ of $\left[\right.$ DOTA ${ }^{0}-\mathrm{Tyr}^{3}$ ]-octreotate. The compound was stored at $-25^{\circ} \mathrm{C}$ until use. ${ }^{177} \mathrm{LuCl}_{3}$ (Perkin Elmer, Life Sciences, Inc., Boston, MA, USA) was diluted in $0.05 \mathrm{M} \mathrm{HCl}$ and mixed with [DOTA ${ }^{0}-\mathrm{Tyr}^{3}$ ]octreotate to a specific activity of $30 \mathrm{MBq} \mu \mathrm{g}^{-1}$. For the biokinetic studies with $0.5 \mathrm{MBq}\left[{ }^{177} \mathrm{Lu}\right.$-DOTA $\left.{ }^{0}-\mathrm{Tyr}^{3}\right]$-octreotate, the specific activity was $0.5 \mathrm{MBq} \mu \mathrm{g}^{-1}$. The mixture was incubated for $30 \mathrm{~min}$ at $80^{\circ} \mathrm{C}$ (de Jong et al, 2001).

[DTPA]-octreotide was labelled with ${ }^{111}$ In according to the manufacturer's instructions (Mallinckrodt Medical B.V., The Netherlands).

The peptide-bound fraction of ${ }^{177} \mathrm{Lu}$ and ${ }^{111} \mathrm{In}$ was assessed by instant thin layer chromatography (ITLC-SG, Gelman, Ann Arbor, MI, USA) with $0.1 \mathrm{~m}$ sodium citrate $(\mathrm{pH}=5.0$, VWR International $\mathrm{AB}$, Sweden) as mobile phase. The fraction of peptide-bound ${ }^{177} \mathrm{Lu}$ and ${ }^{111}$ In was more than $99 \%$.

The exact amount of radiopharmaceutical administered was determined by measuring the activity in the syringes before and after administration of the radiopharmaceutical with a well-type ionisation chamber (CRC-15R, Capintec, NJ, USA).

\section{Biodistribution and biokinetics of ${ }^{177}$ Lu-DOTA ${ }^{0}$-Tyr $\left.{ }^{3}\right]$-octreotate}

For studies of the biodistribution of $\left[{ }^{177} \mathrm{Lu}^{-D O T A}{ }^{0}-\mathrm{Tyr}^{3}\right]$-octreotate, five groups of tumour-bearing animals were injected with a single i.v. injection of 7.5, 15, 30, 60 and $120 \mathrm{MBq}$ of ${ }^{177}$ Lu-DOTATyr $^{3}$-octreotate (30 MBq $\mu \mathrm{g}^{-1}$ ), respectively ( $n=5$ in all groups). The animals were killed $24 \mathrm{~h}$ later and tumour tissue and multiple organs were collected for measurement of radioactivity and histopathological analyses. The ${ }^{177} \mathrm{Lu}$ activity was measured using a Wallac 1480 gamma counter (WIZARD ${ }^{\mathbb{R}} 3^{\prime \prime}$, Wallac, Oy, Finland). Correction was made for detector background and radioactive decay. The activity concentration $(C)$ of the radionuclide was expressed as the fraction of injected activity per unit mass of the tissue ( $\left.\% \mathrm{IA} \mathrm{g}^{-1}\right)$.

For studies of biokinetics, tumour-bearing animals were injected with $0.5 \mathrm{MBq}(1 \mu \mathrm{g}, n=20)$ or $30 \mathrm{MBq}(1 \mu \mathrm{g}, n=20)\left[{ }^{177} \mathrm{Lu}-\right.$ DOTA $^{0}-\mathrm{Tyr}^{3}$ ]-octreotate, that is, diagnostic and therapeutic amounts of radionuclide, respectively. All animals were injected with a single i.v. injection and were killed in groups of five at 1, 3, 7 and 13 days post injection (p.i.), respectively. Control animals $(n=5)$ were untreated. Tumour tissue and multiple organs were collected for measurements of radionuclide uptake and histopathological analyses.

The activity concentration $\left(\% \mathrm{IAg}^{-1}\right)$ was determined for tumour tissue $\left(C_{\mathrm{T}}\right)$ and normal tissue $\left(C_{\mathrm{N}}\right)$. The tumour-to-normal tissue activity concentration ratio (TNC) was calculated according to the formula $\mathrm{TNC}_{\mathrm{N}}=C_{\mathrm{T}} / C_{\mathrm{N}}$.

\section{Dosimetry}

The calculation of the absorbed dose to tumours, kidneys, liver and bone marrow was based on the pharmacokinetics of 0.5 and $30 \mathrm{MBq}\left[{ }^{177} \mathrm{Lu}-\mathrm{DOTA}{ }^{0}-\mathrm{Tyr}^{3}\right]$-octreotate (Loevinger, 1988). The cumulative activity concentration, that is, the total number of radioactive decays per mass unit, was determined by estimating the area under the curve for the activity concentration in each organ $v s$ time. The electron energy emitted per decay was assumed to be $147 \mathrm{keV}$ (Sowby, 1983). The contribution from photons was neglected. Also, the contribution from organs other than the target organ was neglected.

\section{Therapeutic effects of ${ }^{177} \mathrm{Lu}$-DOTA-Tyr ${ }^{3}$-octreotate}

The therapeutic effect of ${ }^{177} \mathrm{Lu}$-octreotate was studied in five groups of tumour-bearing animals given $7.5(0.25 \mu \mathrm{g}, n=6), 15(0.5 \mu \mathrm{g}$, $n=6), 30(1 \mu \mathrm{g}, n=6), 60(2 \mu \mathrm{g}, n=7)$ or $120(4 \mu \mathrm{g}, n=10) \mathrm{MBq}$ of $\left[{ }^{177} \mathrm{Lu}^{-D O T A}{ }^{0}-\mathrm{Tyr}^{3}\right]$-octreotate, respectively. Control animals $(n=11)$ were given $4 \mu \mathrm{g}$ of [DOTA-Tyr ${ }^{3}$ ]-octreotate. Tumour size was measured and the volume was calculated according to the formula $V=4 \pi a b^{2} / 3$ ( $a$ is the longest radius and $b$ is the transverse radius). The animals were followed for 2-7 months. Complete response (CR) was defined as $>99 \%$ reduction of tumour volume. Partial response (PR) was defined as $50-99 \%$ reduction and minor response (MR) as $<50 \%$ reduction of tumour volume.

\section{Biodistribution of [ ${ }^{111}$ In-DTPA]-octreotide}

In order to make it possible to compare the uptake of radiolabelled somatostatin analogue with previous clinical studies, the binding of radiolabelled octreotide was investigated. Each animal $(n=5)$ was injected i.v. with $4 \mathrm{MBq}(0.2 \mu \mathrm{g})$ of $\left[{ }^{111} \mathrm{In}\right.$-DTPA]-octreotide $24 \mathrm{~h}$ before killing. Tumours and blood samples were collected and weighed, and the ${ }^{111}$ In activity in tumour and blood was measured using the gamma counter. The $\mathrm{TNC}_{\mathrm{Blood}}$ was calculated as described above (Forssell-Aronsson et al, 1995).

\section{Morphological analysis}

Morphological analysis was carried out on all tumours included in this study to verify potential therapeutic effects. Tumour tissue from all animals were harvested and fixed in $4 \%$ paraformaldehyde (PF) in PBS at $\mathrm{pH} 7.4$ for $24 \mathrm{~h}$. Specimens were subsequently 
dehydrated and embedded in paraffin wax. Parallel sections were counterstained with haematoxylin (htx) and eosin for morphological analysis, and with Ladewig staining to facilitate the detection of fibrin thrombi in tumour vessels. In all animals given a therapeutic amount of $\left[{ }^{177} \mathrm{Lu}-\mathrm{DOTA}^{0}-\mathrm{Tyr}^{3}\right]$-octreotate, microscopic examination of liver, kidneys and bone marrow was performed in order to reveal any morphological changes related to radiation. Deparaffinised sections were preincubated with $5 \%$ nonfat dry milk followed by incubation overnight with primary antibodies, listed in Table 1. Antiserum was diluted in PBS containing $1 \%$ BSA and $0.1 \%$ sodium azide. Bound antibodies were visualised by the indirect immunoperoxidase technique (EnVision $^{\mathrm{TM}}+$, cat. no. K4000, Dakopatts, Glostrup, Denmark).

\section{Apoptotic cell count}

The number of apoptotic tumour cells was investigated in tumour tissue from the biokinetic study (animals injected with $30 \mathrm{MBq}$ ${ }^{177} \mathrm{Lu}$-octreotate and followed up to 13 days). Haematoxylineosin-stained sections were used to identify apoptotic tumour cells according to morphological criteria (condensed and fragmented nuclei and eosinophilic cytoplasma). Three high power fields (HPF; $\times 40$ objective) were selected from each tumour for counting of apoptotic cells. To obtain representative areas of the tumour, a direction from the centre to the periphery of the tumour was randomly selected. Photographs of each HPF were then systematically taken: (i) in the centre, (ii) half way to the periphery and (iii) in the periphery of the tumour, all along the selected line. The number of apoptotic cells was counted on the photographs and the average number of apoptotic cells per HPF calculated (apoptotic cell count).

\section{Statistical analysis}

Differences between groups regarding uptake of $\left[{ }^{177} \mathrm{Lu}-\mathrm{DOTA}{ }^{0}-\right.$ $\mathrm{Tyr}^{3}$ ]-octreotate, TNC value and apoptotic cell count were analysed by one-way analysis of variance. Logarithmic transformation was used for variance stabilisation. Compensation for multiple comparisons was performed using the Dunnett's method (Hochberg and Tamane, 1987).

Differences in biokinetics between 30 and $0.5 \mathrm{MBq}$ were analysed by two-way analysis of variance followed by $t$-test at each time point. Logarithmic transformation was used for variance stabilisation. Compensation for mass significance was performed according to Bonferroni-Holm (Hochberg and Tamane, 1987).

For analysis of the therapeutic effect of $\left[{ }^{177} \mathrm{Lu}-\mathrm{DOTA}{ }^{0}-\mathrm{Tyr}^{3}\right]$ octreotate, the number of $\mathrm{CR}$ in the treatment groups (7.5$120 \mathrm{MBq}$ ) was compared to the number of CR in the control group using Fisher's exact test. Compensation for mass significance was performed according to Bonferroni-Holm.

$P$-values $<0.05$ were considered significant.

\section{RESULTS}

\section{Biodistribution of $\left[{ }^{177} \mathrm{Lu}^{\mathrm{DOOTA}}{ }^{0}\right.$-Tyr $\left.{ }^{3}\right]$-octreotate}

Five groups of tumour-bearing animals were given 7.5, 15, 30, 60 and $120 \mathrm{MBq}\left[{ }^{177} \mathrm{Lu}-\mathrm{DOTA}^{0}-\mathrm{Tyr}^{3}\right]$-octreotate, respectively. The maximum uptake of $\left[{ }^{177} \mathrm{Lu}-\mathrm{DOTA}{ }^{0}-\mathrm{Tyr}^{3}\right]$-octreotate in GOT1 tumours $24 \mathrm{~h}$ p.i. was seen both in animals given 7.5 and $15 \mathrm{MBq}$ and reached $17 \pm 3 \% \mathrm{IAg}^{-1}$ (mean \pm s.e.m.). In animals given larger amounts of activity, the uptake declined, indicating saturation of sstr in tumour tissue.

In normal tissues, the uptake was generally lower than in tumours. The highest uptake was found in the kidneys (6.1$7.7 \% \mathrm{IA} \mathrm{g}^{-1}$ ) (Figure 1). For all other organs (liver, spleen, small intestine, blood, skeletal muscle, heart, brain, lungs, pancreas and adrenals), the uptake was very low $(0.01-1.7) \% \mathrm{IAg}^{-1}$. For kidneys, liver, blood, skeletal muscle, heart and brain, the uptake was independent of the amount of activity administered, which indicates no saturation, or nonspecific distribution in the tissues. However, in the spleen, small intestine, lungs, pancreas and adrenals, the uptake was highest for $7.5 \mathrm{MBq}\left[{ }^{177} \mathrm{Lu}-\mathrm{DOTA}{ }^{0}-\mathrm{Tyr}^{3}\right]$ octreotate and declined with increasing amounts of $\left[{ }^{177} \mathrm{Lu}\right.$-DOTA ${ }^{0}$ $\left.\mathrm{Tyr}^{3}\right]$-octreotate, which indicates saturation of receptor-mediated binding.

\section{Biokinetics of $\left[{ }^{177} \mathrm{Lu}-\mathrm{DOTA}{ }^{0}-\mathrm{Tyr}^{3}\right]$-octreotate}

In order to compare the biokinetics of $\left[{ }^{177} \mathrm{Lu}-\mathrm{DOTA}{ }^{0}-\mathrm{Tyr}^{3}\right]-$ octreotate after diagnostic and therapeutic amounts, two groups of animals were injected with 0.5 and $30 \mathrm{MBq}\left[{ }^{177} \mathrm{Lu}^{-D O T A}{ }^{0}-\mathrm{Tyr}^{3}\right]$ octreotate, respectively. The specific activity of $\left[{ }^{177} \mathrm{Lu}-\mathrm{DOTA}{ }^{0}-\right.$ $\mathrm{Tyr}^{3}$ ]-octreotate in the diagnostic group was lower, that is, the amount of peptide $(1 \mu \mathrm{g})$ was identical in both groups.

The uptake of $\left[{ }^{177} \mathrm{Lu}\right.$-DOTA $\left.{ }^{0}-\mathrm{Tyr}^{3}\right]$-octreotate in tumours was similar for both groups of animals $24 \mathrm{~h}$ p.i. However, the biokinetics of the activity concentration differed significantly between the two groups. In animals given $0.5 \mathrm{MBq}\left[{ }^{177} \mathrm{Lu}\right.$-DOTA ${ }^{0}$ $\mathrm{Tyr}^{3}$ ]-octreotate, which did not retard tumour growth, the activity concentration declined over time and was less than $50 \%$ at 7 days and less than $20 \%$ at 13 days p.i. compared to the initial concentration. In contrast, in animals given $30 \mathrm{MBq}$, the activity concentration remained high over time and the biokinetic curves differed significantly both at 7 days p.i. $(P=0.00044)$ and 13 days p.i. $(P=0.00081)$ (Figure 2$)$. The tumour volumes at 7 days p.i. and 13 days p.i. for animals given $30 \mathrm{MBq}$ were reduced to $16 \pm 8.5$ and $11 \pm 4.2 \%$ (mean \pm s.e.m.) compared to the initial volumes.

\section{Tumour-to-normal tissue activity concentration ratio}

Tumour-to-normal tissue activity concentration ratios of $\left[{ }^{177} \mathrm{Lu}-\right.$ DOTA $^{0}-$ Tyr $\left.^{3}\right]$-octreotate were determined up to 13 days after a single injection of $30 \mathrm{MBq}$. In general, the TNC value increased compared to the situation at $24 \mathrm{~h}$ p.i., which indicates a favourable change over time for the radiation to the tumour in relation to the radiation received by liver, kidneys and bone marrow. The increase in TNC value at 7 days p.i., compared to $24 \mathrm{~h}$ p.i., was significant for the bone marrow $(P=0.0031)$, liver $(P=0.033)$ as well as for the kidneys $(P=0.00015)$ (Figure 3$)$.

\section{Dosimetry}

Tumours treated with $30 \mathrm{MBq}$ received about $120 \mathrm{~Gy}$, corresponding to $4.0 \mathrm{~Gy} \mathrm{MBq}^{-1}$, when the absorbed dose was calculated using biokinetic data for the therapeutic amount of $30 \mathrm{MBq}$. For normal

Table I Primary antibodies used for immunocytochemistry

\begin{tabular}{|c|c|c|c|c|}
\hline Antibody & Dilution & Clone & Cat. no & Company \\
\hline CgA (monoclonal, anti-human) & $1: 1000$ & LK2HIO & | | 9902 | & Boehringer Mannheim, Mannheim, Germany \\
\hline Ki-67 (monoclonal, anti-human) & $1: 100$ & MIB-I & & DAKO, Glostrup, Denmark \\
\hline CD 3 (monoclonal, anti-human) & $1: 100$ & & M7254 & DAKO, Glostrup, Denmark \\
\hline CD 20 (M-20, goat anti-mouse) & $1: 50$ & & Sc-7735 & Santa Cruz Biotechnology, Inc., Santa Cruz, CA, USA \\
\hline
\end{tabular}




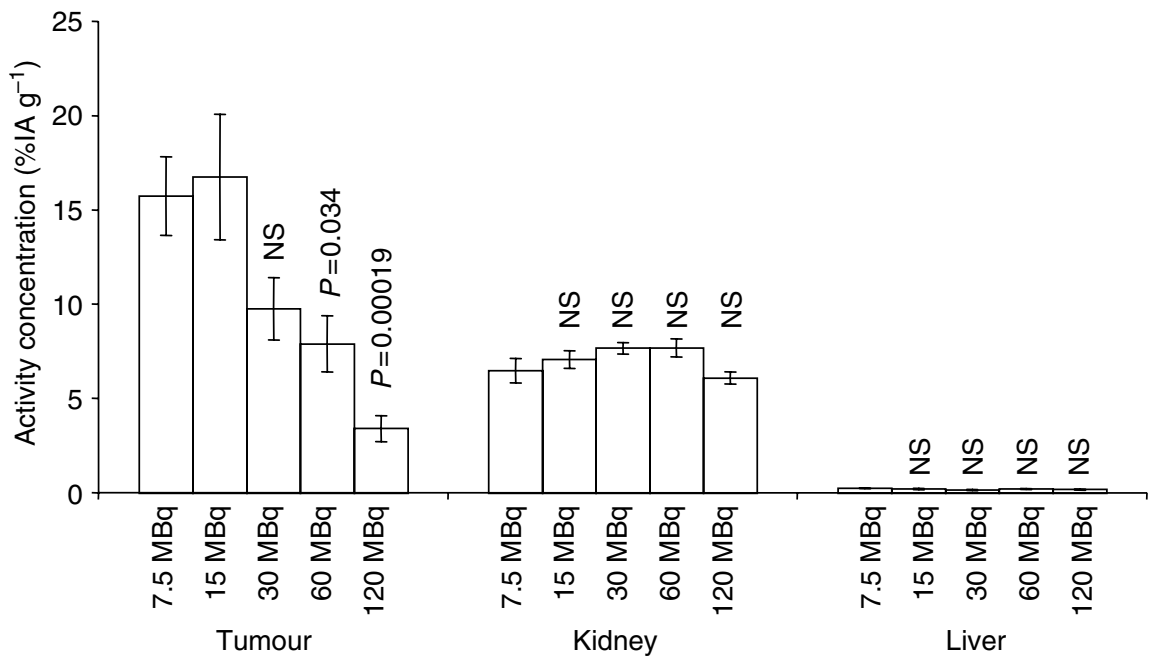

Figure I Uptake of [ ${ }^{177} \mathrm{Lu}$-DOTA $\left.{ }^{0}-\mathrm{Tyr}^{3}\right]$-octreotate was studied in tumours as well as in several organs $24 \mathrm{~h}$ p.i. In the tumours, the maximum uptake was $17 \pm 3.3 \% \mathrm{Ag}^{-1}$ (mean \pm s.e.m. $n=5$ for all groups) and was seen in animals receiving $15 \mathrm{MBq}(0.5 \mu \mathrm{g})$ and $7.5 \mathrm{MBq}(0.25 \mu \mathrm{g})$ [ $\left.{ }^{177} \mathrm{Lu}-\mathrm{DOTA} \mathrm{A}^{0}-\mathrm{Tyr}^{3}\right]$ octreotate. Decreasing uptake for higher administered doses indicated saturation of sstr in tumour tissue. For the critical organs kidney and liver, no signs of saturation was seen. P-values reflect the difference vs $7.5 \mathrm{MBq}$.

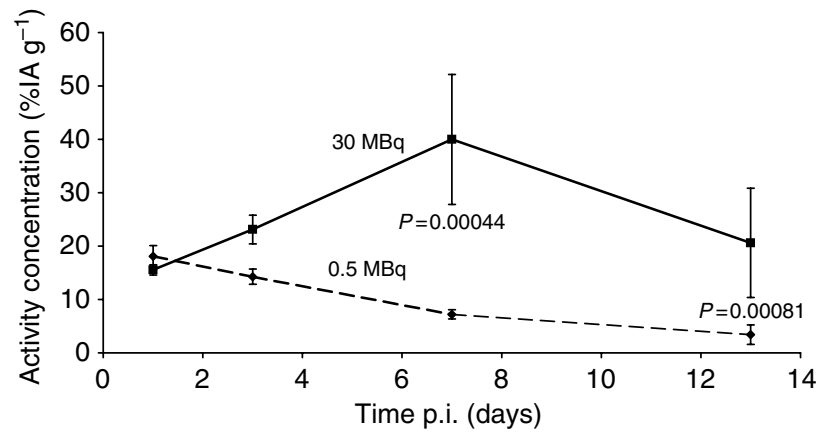

Figure 2 The biokinetics of $\left[{ }^{177}\right.$ Lu-DOTA $\left.{ }^{0}-T_{y r}{ }^{3}\right]$-octreotate after a diagnostic amount $(0.5 \mathrm{MBq})$ as well as after a therapeutic amount $(30 \mathrm{MBq})$ was studied in two groups of animals injected with [ ${ }^{177} \mathrm{Lu}$ DOTA ${ }^{0}-\mathrm{Tyr}^{3}$ ]-octreotate. In the animals receiving $0.5 \mathrm{MBq}\left[{ }^{177} \mathrm{Lu}^{\mathrm{LOOTA}}{ }^{0}\right.$ $\mathrm{Tyr}^{3}$ ]-octreotate, the activity concentration declined over time. On the contrary, in animals receiving $30 \mathrm{MBq}$, the activity concentration was retained over time and the biokinetic curves differed significantly both at 7 days p.i. $(P=0.00044)$ and 13 days p.i. $(P=0.00081)$. The values are presented as mean \pm s.e.m., $n=5$ at all time points for both groups.

tissues in animals given $30 \mathrm{MBq}$, the absorbed doses were $0.15 \mathrm{~Gy}$ to bone marrow, $0.68 \mathrm{~Gy}$ to liver and $8.7 \mathrm{~Gy}$ to kidneys, respectively. The diagnostic amount $0.5 \mathrm{MBq}$, with clearly different biokinetics, resulted in $1.6 \mathrm{~Gy} \mathrm{MBq}^{-1}$ to the tumours.

\section{Therapeutic effects of $\left[{ }^{177} \mathrm{Lu}\right.$-DOTA ${ }^{0}$-Tyr $\left.{ }^{3}\right]$-octreotate}

Five groups of tumour-bearing animals were injected with 7.5, 15, 30,60 and $120 \mathrm{MBq}{ }^{177} \mathrm{Lu}$-DOTA-Tyr ${ }^{3}$-octreotate, respectively. Control animals were given $4 \mu \mathrm{g}$ of unlabelled DOTA-Tyr ${ }^{3}$ octreotate. The tumours in control animals grew rapidly and doubled their volumes after 2 weeks. Treatment with $\left[{ }^{177} \mathrm{Lu}-\right.$ DOTA $^{0}-\mathrm{Tyr}^{3}$ ]-octreotate resulted in a rapid and dose-dependent reduction of tumour volume (Figure 4). The number of $\mathrm{CR}$ increased significantly with increasing amounts of $\left[{ }^{177} \mathrm{Lu}^{\mathrm{D}} \mathrm{DOTA}{ }^{0}\right.$ $\mathrm{Tyr}^{3}$ ]-octreotate administered (Table 2).

After treatment with $30 \mathrm{MBq}$, one out of six animals with $\mathrm{CR}$ remained free of recurrent tumour until being killed 3 months

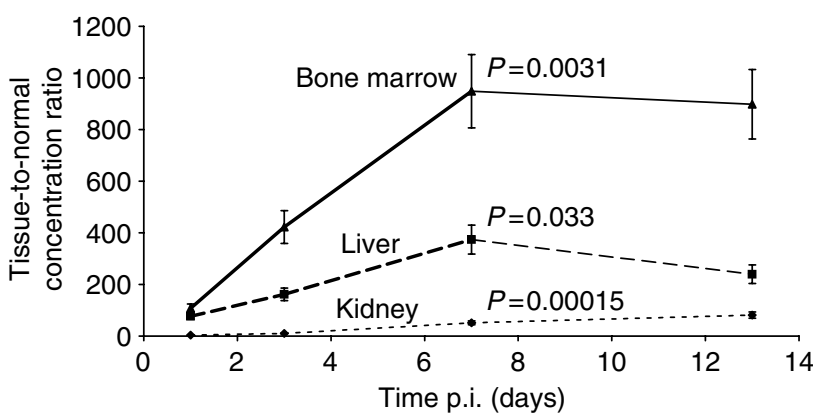

Figure 3 Tumour-to-normal tissue activity concentration ratio (TNC) of [ 1 Lu-DOTA ${ }^{0}-$ Tyr $^{3}$ ]-octreotate followed up to 13 days after a single injection of $30 \mathrm{MBq}$. At 3, 7 and 13 days p.i., the TNC value increased compared to the situation I day p.i. This indicates a favourable relation over time for the radiation to the tumour in comparison with the radiation to the critical organs liver, kidney and bone marrow. P-values reflect the difference vs I day p.i.

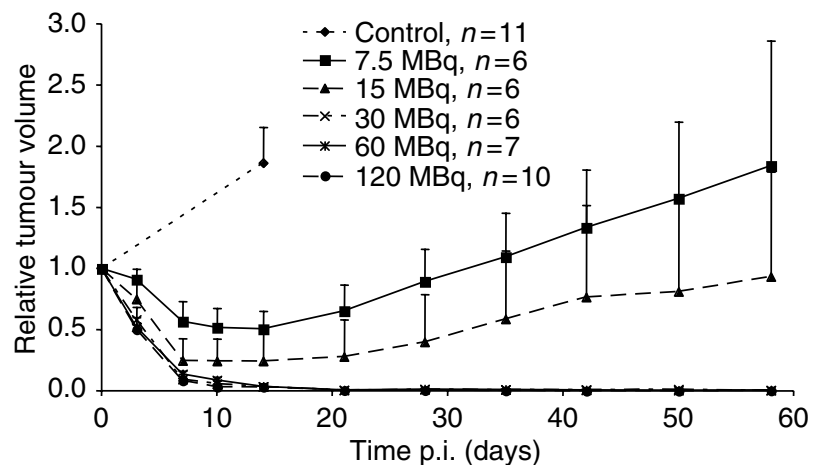

Figure 4 Treatment with [ $\left.{ }^{177} \mathrm{Lu}-\mathrm{DOTA} \mathrm{A}^{0}-\mathrm{Tyr}^{3}\right]$-octreotate resulted in a rapid, dose-dependent reduction of tumour volume. For animals receiving 7.5 and $15 \mathrm{MBq}$, the effect was moderate and temporary, whereas for animals receiving $30 \mathrm{MBq} C R$ was achieved. In animals treated with 30, 60 or $120 \mathrm{MBq}, 22$ out of 23 animals had CR. The tumour volume presented is the mean volume \pm s.e.m. for each group, set to $\mid$ at the start of the experiment. The $P$-values for the number of $C R$ for animals treated with 30,60 and $120 \mathrm{MBq}$ vs controls are $0.00032,0.001 \mathrm{I}$ and 0.000014 , respectively. 
Table 2 Result of therapy with [ ${ }^{177}$ Lu-DOTA $\left.^{0}-\mathrm{Tyr}^{3}\right]$-octreotate

\begin{tabular}{|c|c|c|c|}
\hline $\begin{array}{l}\text { Administered amount } \\
\text { of }{ }^{177} \text { Lu-DOTA-Tyr }{ }^{3} \text { - } \\
\text { octreotate }\end{array}$ & $\begin{array}{l}\text { Complete response } \\
\text { (CR), >99\% reduction } \\
\text { of tumour volume, } \\
P \text {-value vs controls }\end{array}$ & $\begin{array}{c}\text { Partial response (PR) } \\
50-99 \% \text { reduction of } \\
\text { tumour volume }\end{array}$ & $\begin{array}{c}\text { Minor response (MR) } \\
<\mathbf{5 0 \%} \text { reduction of } \\
\text { tumour volume }\end{array}$ \\
\hline $0 \mathrm{MBq}, n=1 \mathrm{I}$ (controls) & 0 & 0 & 0 \\
\hline $7.5 \mathrm{MBq}, n=6$ & $0 \mathrm{NS}$ & 3 & 3 ( $33-46 \%$ reduction) \\
\hline $15 \mathrm{MBq}, n=6$ & $2 N S$ & 3 & | (49\% reduction) \\
\hline $30 \mathrm{MBq}, n=6$ & $6 P=0.00032$ & - & - \\
\hline $60 \mathrm{MBq}, n=7$ & $6 P=0.0011$ & I (98\% reduction) & - \\
\hline $120 \mathrm{MBq}, n=10$ & $10 P=0.000014$ & & - \\
\hline
\end{tabular}

NS = nonsignificant.

later. After $60 \mathrm{MBq}$, two out of six animals with $\mathrm{CR}$ remained free of recurrence until being killed $6-7$ months later. After treatment with $120 \mathrm{MBq}$, six out of 10 animals with CR remained free of recurrence until being killed 3-4 months after the remission (Figure 4).

\section{Biodistribution of $\left[{ }^{111}\right.$ In-DTPA]-octreotide}

The activity concentration of $\left[{ }^{111}\right.$ In-DTPA]-octreotide in GOT1 tumours $24 \mathrm{~h}$ p.i. was $8.2 \pm 2.0 \% \mathrm{IAg}^{-1}$ (mean \pm s.e.m.). The $\mathrm{TNC}_{\text {Blood }}$ for [ ${ }^{111}$ In-DTPA]-octreotide was then $410 \pm 70$ (mean \pm s.e.m.).

\section{Induction of apoptosis and necrosis after treatment with $\left[{ }^{177}\right.$ Lu-DOTA ${ }^{0}$-Tyr $\left.{ }^{3}\right]$-octreotate}

In untreated controls, tumour cells grew in solid sheets with small variation in nuclear size and without necroses. The tumour cells were positive for the general NE-marker CgA, serotonin (5-HT) and Vesicular Mono Amine Transporters (VMAT1 and 2). In animals treated with $30 \mathrm{MBq}\left[{ }^{177} \mathrm{Lu}\right.$-DOTA $\left.{ }^{0}-\mathrm{Tyr}^{3}\right]$-octreotate, a significant increase in apoptotic cell count, compared to controls, was observed both at 1 day p.i. $(P=0.0000030)$ and 3 days p.i. $(P=0.00000059)$. In animals killed 3 days p.i., all five tumours had large confluent necroses and intercellular oedema. In animals, killed 7 and 13 days p.i., the number of tumour cells was clearly reduced as was the apoptotic cell count and the oedema and necroses were replaced by fibrosis. The typical appearance of a tumour 13 days p.i. was that of almost complete fibrosis and absence of tumour cells (Figure 5). The apoptotic cell count at each time point is presented in Figure $5 \mathrm{~F}$.

In the therapy groups $(7.5-120 \mathrm{MBq})$, all tumours, or tumour residues, were morphologically examined at the end of the observation period. Gross examination of the small residual tumour tissue, found in animals with $\mathrm{CR}$ in response to $\left[{ }^{177} \mathrm{Lu}-\right.$ DOTA ${ }^{0}-$ Tyr $^{3}$ ]-octreotate, revealed brownish nodules, $1-2 \mathrm{~mm}$ in diameter. The microscopic analysis demonstrated a thin rim of fibroblasts in the periphery and a central part consisting of crystalline structures surrounded by inflammatory cells including macrophages and giant cells (Figure 6). Specific staining for fibrin (Ladewig) did not show any signs of thrombosis in treated tumours.

\section{Side effects of radiation}

Morphologic analysis of the liver, kidneys and bone marrow after ${ }^{177} \mathrm{Lu}$-DOTA $\left.^{0}-\mathrm{Tyr}^{3}\right]$-octreotate therapy revealed two animals with reactive inflammatory response in the portal fields of the liver. These inflammatory infiltrates were composed both of $\mathrm{CD} 3-$ positive $\mathrm{T}$ cells and $\mathrm{CD}$ 20-positive $\mathrm{B}$ cells and had a Ki-67 proliferative index of $<1 \%$. In one animal, the kidney contained a fibrous scar. The bone marrow of all animals was normal with preserved haematopoietic cells.

\section{DISCUSSION}

This study presents the first systematic optimisation of sstrmediated radiation therapy with $\left[{ }^{177} \mathrm{Lu}\right.$-DOTA $\left.{ }^{0}-\mathrm{Tyr}^{3}\right]$-octreotate of a human midgut carcinoid xenografted to nude mice. The first part of the study demonstrated that saturation of sstr in the tumours after a single i.v injection of $\left[{ }^{177} \mathrm{Lu}\right.$-DOTA $\left.{ }^{0}-\mathrm{Tyr}^{3}\right]$-octreotate was evident between $0.5 \mu \mathrm{g}(15 \mathrm{MBq})$ and $1 \mu \mathrm{g}(30 \mathrm{MBq})$. It is important to define this level, since suboptimal therapeutic amounts will not lead to maximal uptake and maximal absorbed doses in the tumours. The uptake, and hence the absorbed dose, in the kidneys, liver and bone marrow increased proportionally to the amounts administered. Therefore, amounts in excess of the tumour saturation level will increase adverse effects of radiation therapy.

The second part of the study described the markedly different biokinetics of $\left[{ }^{177} \mathrm{Lu}\right.$-DOTA $\left.{ }^{0}-\mathrm{Tyr}^{3}\right]$-octreotate, given in diagnostic $v s$ therapeutic amounts. The activity concentration in tumours after being given diagnostic amounts $(0.5 \mathrm{MBq}, 1 \mu \mathrm{g})$ was reduced over time. On the other hand, in tumours from animals given a therapeutic amount $(30 \mathrm{MBq}, 1 \mu \mathrm{g})$, the concentration remained high over time and significantly differed from the animals given a diagnostic amount both at 7 and 13 days p.i. The preserved high activity concentration in the therapy group was unexpected and significantly contributed to the high absorbed doses in the tumours, and thereby a very high efficacy of the radiation therapy. The difference in biokinetics can to a large extent be explained by tumour shrinkage, but other factors may also be of importance, for example, upregulation of sstr expression, radionuclide sequestration, increased intratumoural pressure and changed tumour blood flow initiated by the radiation.

The entrapment of radionuclide and altered biokinetics in the tumours after a therapeutic amount resulted in significantly increased TNC values over time. Therefore, choice of a radionuclide with half-life long enough to take advantage of this favourable change is essential when sstr-mediated radiation therapy is planned.

The third part of the study showed dose-dependent tumour responses. In animals treated with 7.5 and $15 \mathrm{MBq}\left[{ }^{177} \mathrm{Lu}-\mathrm{DOTA}{ }^{0}-\right.$ $\mathrm{Tyr}^{3}$ ]-octreotate, the absorbed doses were low and CR was seen only occasionally. These tumours started to grow again after 2 weeks of reduced volume. In animals treated with $30-120 \mathrm{MBq}$ $\left[{ }^{177} \mathrm{Lu}\right.$-DOTA $\left.{ }^{0}-\mathrm{Tyr}^{3}\right]$-octreotate, the absorbed doses were high; all, but one, of these animals showed CR. It is very unusual to obtain $\mathrm{CR}$ in animal tumour models using radionuclide therapy. Besides the present study and our previous study on $\left[{ }^{177} \mathrm{Lu}-\mathrm{DOTA}{ }^{0}-\mathrm{Tyr}^{3}\right]$ octreotate therapy in the human small-cell lung cancer cell line NCI-H69 xenografted to nude mice, CR is very unusual (de Jong et al, 2001; Schmitt et al, 2004). For a long period, carcinoid 

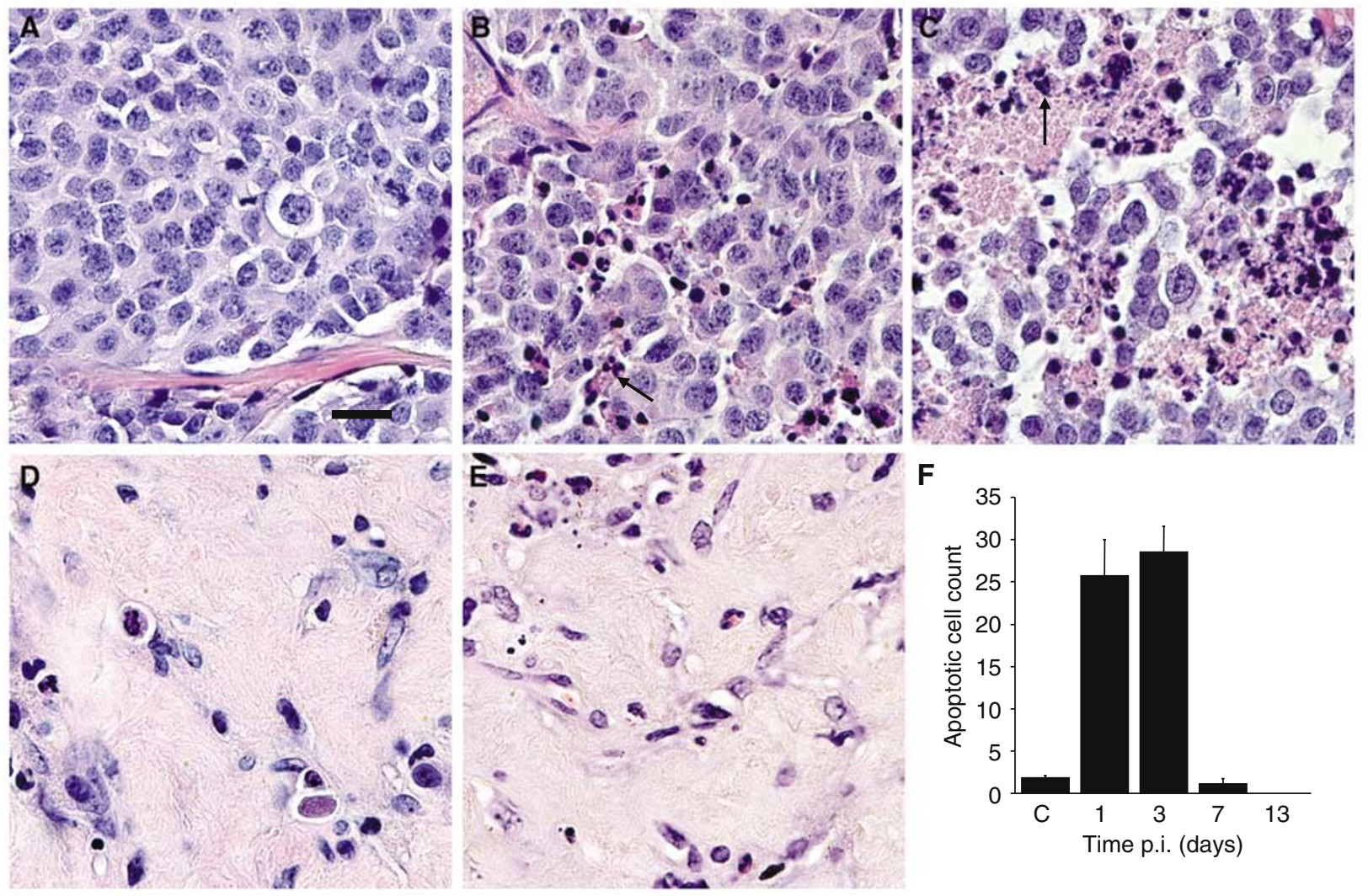

Figure 5 Typical morphological appearance of GOTI tumours I day $(\mathbf{B}), 3$ days $(\mathbf{C}), 7$ days $(\mathbf{D})$ and I 3 day (E) after treatment with 30 MBq [ ${ }^{177}$ LuDOTA ${ }^{0}-$ Tyr $\left.^{3}\right]$-octreotate compared to an untreated tumour $(\mathbf{A})$. After injection of $\left[{ }^{17} \mathrm{Lu}\right.$-DOTA ${ }^{0}$-Tyr ${ }^{3}$-octreotate, significant increases in the apoptotic cell count vs controls could be seen both I day p.i. $(P=0.0000030)$ and 3 day p.i. $(P=0.00000059)$. At 3 days p.i., all five tumours presented with large confluent necroses and oedema. At 7 and 13 days p.i., the apoptotic cell count decreased and the oedema and necroses were gradually replaced by fibrosis. The apoptotic cell count was $1.9 \pm 0.29$ (mean \pm s.e.m.) for control animals and $26 \pm 4.3,29 \pm 3.1,1.2 \pm 0.65$ and $0 \pm 0$ at I, 3, 7 and I 3 days p.i., respectively (F). Typically, apoptotic cells (condensed and fragmented nuclei and eosinophilic cytoplasma) are indicated by arrows. Scale bar equals $20 \mu \mathrm{m}$.

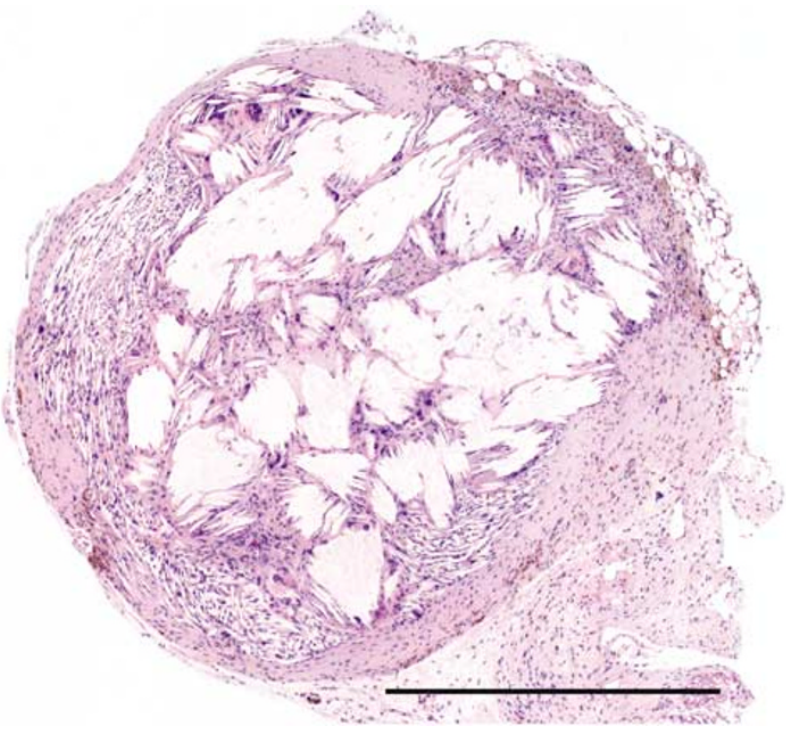

Figure 6 Histopathological analysis of a small remnant of tumour tissue in an animal with CR 5 months after administration of $120 \mathrm{MBq}\left[{ }^{177} \mathrm{Lu}\right.$ DOTA $\left.{ }^{0}-T_{y r}{ }^{3}\right]$-octreotate. The tumour residue consisted of a brownish nodule ( $2 \mathrm{~mm}$ in diameter). In the periphery, only a thin rim of fibroblasts was found. The dominant part of the nodule contained crystalline structures surrounded by inflammatory cells including macrophages and giant cells. Scale bar equals $1 \mathrm{~mm}$. tumours were considered to be resistant to radiation therapy. However, a palliative role for both external radiation and ${ }^{131} \mathrm{I}$ MIBG radiation therapy of NE tumours was proposed some 10 years ago (Samlowski et al, 1986; Kimmig, 1994). The present study clearly shows that human midgut carcinoid xenografts can be cured by adequate radiation therapy with minimal adverse effects.

Sstr-mediated radiation therapy using $\left[{ }^{177} \mathrm{Lu}^{-D_{0 T A}}{ }^{0}-\mathrm{Tyr}^{3}\right]-$ octreotate in clinical series of patients with large tumour burden has not resulted in high rates of CR, most probably due to the administration of suboptimal amounts of radiopharmaceutical (Kwekkeboom et al, 2003). Our experiments show the importance of defining the amount of peptide required to achieve receptor saturation. This should, therefore, be included as part of the dose planning before therapy. Also correct choice of radionuclide and somatostatin analogue is of importance to obtain a high absorbed dose, which is a pre-requisite for a good tumour response (Bernhardt et al, 2001; Bernhardt et al, 2003a).

The present study not only showed a high cure rate of human midgut carcinoids but also revealed an unexpected entrapment of ${ }^{177} \mathrm{Lu}$ in tumour tissue during therapy. As recently shown in a patient with limited lymphoglandular spread of midgut carcinoid tumour, $\left[{ }^{177} \mathrm{Lu}-\mathrm{DOTA}{ }^{0}-\mathrm{Tyr}^{3}\right]$-octreotate has the potential to induce almost complete remission (Ahlman et al, 2004). GOT1 cells were harvested from the first patient, who underwent therapy with $\left[{ }^{111}\right.$ In-DTPA]-octreotide. The biological characteristics of GOT1 closely resemble the tumour of the original patient, that is, preserved neuroendocrine differentiation and molecular markers, 
type of treatment can be transferred to the clinical situation with high success rate.

$\left[{ }^{111}\right.$ In-DTPA]-octreotide uptake (Fjälling et al, 1996; Kölby et al, 2001). In other aspects, that is, subcutaneous tumour localisation and more rapid tumour growth, the model differs from the human situation. An orthotopic model, with liver metastases, would be very helpful to further resemble the clinical situation. The exceptional results obtained in GOT1 xenografts may thus indicate a possibility for more successful treatment of patients with metastatic carcinoid tumours than hitherto achieved in clinical series. In the individual patient, determination of sstr expression profiles in tumours by real-time quantitative PCR may be helpful to select the best somatostatin analogue to obtain maximal uptake of the radiopharmaceutical. Also, a radionuclide with suitable range in relation to the volumes of the tumours intended to be treated is important (Bernhardt et al, 2001). Determination of the specific uptake in tumours (studied in biopsies or determined by octreotide scintigraphy) can also be helpful to estimate the absorbed dose and expected biological effect (Forssell-Aronsson et al, 1995). In the future, the dose dependency of the shown entrapment as well as the tolerance of normal tissues to sstrmediated radiation therapy must be studied in detail before this

\section{REFERENCES}

Ahlman H, Nilsson O, Olausson M (2004) Interventional treatment of the carcinoid syndrome. Neuroendocrinology 80(Suppl 1): 67-73

Ahlman H, Wängberg B, Jansson S, Friman S, Olausson M, Tylen U, Nilsson O (2000) Interventional treatment of gastrointestinal neuroendocrine tumours. Digestion 62(Suppl 1): 59-68

Ahlman H, Wängberg B, Tisell LE, Nilsson O, Fjälling M, Forssell-Aronsson E (1994) Clinical efficacy of octreotide scintigraphy in patients with midgut carcinoid tumours and evaluation of intraoperative scintillation detection. Br J Surg 81: 1144-1149

Bernhardt P, Ahlman H, Forssell-Aronsson E (2003a) Model of metastatic growth valuable for radionuclide therapy. Med Phys 30: 3227-3232

Bernhardt $\mathrm{P}$, Ahlman $\mathrm{H}$, Nilsson $\mathrm{O}$, Benjegård SA, Forssell-Aronsson $\mathrm{E}$ (2003b) Evaluation of (111)In labeled somatostatin analogs for targeted therapy of somatostatin receptor positive tumors. Cancer Biother Radiopharm 18: $249-252$

Bernhardt P, Benjegard SA, Kölby L, Johanson V, Nilsson O, Ahlman H, Forssell-Aronsson E (2001) Dosimetric comparison of radionuclides for therapy of somatostatin receptor-expressing tumors. Int J Radiat Oncol Biol Phys 51: 514-524

Bousquet C, Puente E, Buscail L, Vaysse N, Susini C (2001) Antiproliferative effect of somatostatin and analogs. Chemotherapy 47(Suppl 2): 30-39

Cimitan M, Buonadonna A, Cannizzaro R, Canzonieri V, Borsatti E, Ruffo $\mathrm{R}$, De Apollonia L (2003) Somatostatin receptor scintigraphy $v s$ chromogranin A assay in the management of patients with neuroendocrine tumors of different types: clinical role. Ann Oncol 14: $1135-$ 1141

de Jong M, Bakker WH, Krenning EP, Breeman WA, van der Pluijm ME, Bernard BF, Visser TJ, Jermann E, Behe M, Powell P, Macke HR (1997) Yttrium-90 and indium-111 labelling, receptor binding and biodistribution of [DOTA0,d-Phe1,Tyr3] octreotide, a promising somatostatin analogue for radionuclide therapy. Eur J Nucl Med 24: 368-371

de Jong M, Bernard BF, De Bruin E, Van Gameren A, Bakker WH, Visser TJ, Mäcke HR, Krenning EP (1998) Internalization of radiolabelled [DTPA0]octreotide and [DOTA0,Tyr3]octreotide: peptides for somatostatin receptor-targeted scintigraphy and radionuclide therapy. $\mathrm{Nucl} \mathrm{Med}$ Commun 19: $283-288$

de Jong M, Breeman WA, Bernard BF, Bakker WH, Schaar M, van Gameren A, Bugaj JE, Erion J, Schmidt M, Srinivasan A, Krenning EP (2001) 177Lu-DOTA(0),Tyr3] octreotate for somatostatin receptor-targeted radionuclide therapy. Int J Cancer 92: 628-633

Eriksson B, Öberg K (1999) Summing up 15 years of somatostatin analog therapy in neuroendocrine tumors: future outlook. Ann Oncol 10(Suppl 2): $\mathrm{S} 31-\mathrm{S} 38$

Fjälling M, Andersson P, Forssell-Aronsson E, Gretarsdottir J, Johansson V, Tisell LE, Wängberg B, Nilsson O, Berg G, Michanek A, Lindstedt G, Ahlman H (1996) Systemic radionuclide therapy using indium-111-
DTPA-D-Phe1-octreotide in midgut carcinoid syndrome. J Nucl Med 37: $1519-1521$

Forssell-Aronsson E, Fjälling M, Nilsson O, Tisell LE, Wängberg B, Ahlman $\mathrm{H}$ (1995) Indium-111 activity concentration in tissue samples after intravenous injection of indium-111-DTPA-D-Phe-1-octreotide. $\mathrm{J} \mathrm{Nucl}$ Med 36: 7-12

Hellman P, Lundström T, Öhrvall U, Eriksson B, Skogseid B, Öberg K, Tiensuu Janson E, Åkerström G (2002) Effect of surgery on the outcome of midgut carcinoid disease with lymph node and liver metastases. World J Surg 26: $991-997$

Hochberg Y, Tamane AC (1987) Multiple Comparison Procedures. New

Kimmig BN (1994) Radiotherapy for gastroenteropancreatic neuroendocrine tumors. Ann N Y Acad Sci 733: 488-495

Kölby L, Bernhardt P, Ahlman H, Wängberg B, Johanson V, Wigander A, Forssell-Aronsson E, Karlsson S, Ahrén B, Stenman G, Nilsson O (2001) A transplantable human carcinoid as model for somatostatin receptormediated and amine transporter-mediated radionuclide uptake. Am J Pathol 158: $745-755$

Kölby L, Persson G, Franzén S, Ahrén B (2003) Randomized clinical trial of the effect of interferon alpha on survival in patients with disseminated midgut carcinoid tumours. Br J Surg 90: 687-693

Krenning EP, de Jong M, Kooij PP, Breeman WA, Bakker WH, de Herder WW, van Eijck CH, Kwekkeboom DJ, Jamar F, Pauwels S, Valkema R (1999) Radiolabelled somatostatin analogue(s) for peptide receptor scintigraphy and radionuclide therapy. Ann Oncol 10(Suppl 2): S23-S29

Krenning EP, Kwekkeboom DJ, Bakker WH, Breeman WA, Kooij PP, Oei HY, van Hagen M, Postema PT, de Jong M, Reubi JC, Visser TJ, Reijs AEM, Hofland LJ, Koper JW, Lamberts SWJ (1993) Somatostatin receptor scintigraphy with [111In-DTPA-D-Phe1]- and [123I-Tyr3]octreotide: the Rotterdam experience with more than 1000 patients. Eur J Nucl Med 20: 716-731

Kwekkeboom DJ, Bakker WH, Kam BL, Teunissen JJ, Kooij PP, de Herder WW, Feelders RA, van Eijck $\mathrm{CH}$, de Jong M, Srinivasan A, Erion JL, Krenning EP (2003) Treatment of patients with gastro-entero-pancreatic (GEP) tumours with the novel radiolabelled somatostatin analogue [177Lu-DOTA(0),Tyr3] octreotate. Eur J Nucl Med Mol Imaging 30: $417-422$

Loevinger R (1988) Primer for Absorbed Dose Calculations. New York: Society of Nuclear Medicine

McCarthy KE, Woltering EA, Espenan GD, Cronin M, Maloney TJ, Anthony LB (1998) In situ radiotherapy with ${ }^{111}$ In-pentetreotide: initial observations and future directions. Cancer J Sci Am 4: 94-102

McEntee GP, Nagorney DM, Kvols LK, Moertel CG, Grant CS (1990) Cytoreductive hepatic surgery for neuroendocrine tumors. Surgery 108: $1091-1096$ York: John Wiley \& Sons Inc. 
Modlin IM, Lye KD, Kidd M (2003) A 5-decade analysis of 13715 carcinoid tumors. Cancer 97: $934-959$

Moertel CG, Johnson CM, McKusick MA, Martin Jr JK, Nagorney DM, Kvols LK, Rubin J, Kunselman S (1994) The management of patients with advanced carcinoid tumors and islet cell carcinomas. Ann Intern Med 120: 302 - 309

Nilsson O, Kölby L, Wängberg B, Wigander A, Billig H, William-Olsson L, Fjälling M, Forssell-Aronsson E, Ahlman H (1998) Comparative studies on the expression of somatostatin receptor subtypes, outcome of octreotide scintigraphy and response to octreotide treatment in patients with carcinoid tumours. Br J Cancer 77: 632-637

Öberg K. (1993) The use of chemotherapy in the management of neuroendocrine tumors. Endocrinol Metab Clin North Am 22: 941 - 952

Öberg K (1999) Neuroendocrine gastrointestinal tumors - a condensed overview of diagnosis and treatment. Ann Oncol 10(Suppl 2): S3-S8

Paganelli G, Zoboli S, Cremonesi M, Bodei L, Ferrari M, Grana C, Bartolomei M, Orsi F, De Cicco C, Mäcke HR, Chinol M, de Braud F (2001) Receptor-mediated radiotherapy with 90Y-DOTA-D-Phe1-Tyr3octreotide. Eur J Nucl Med 28: 426-434

Reubi JC, Schar JC, Waser B, Wenger S, Heppeler A, Schmitt JS, Mäcke HR (2000) Affinity profiles for human somatostatin receptor subtypes SST1 SST5 of somatostatin radiotracers selected for scintigraphic and radiotherapeutic use. Eur J Nucl Med 27: 273-282
Samlowski WE, Eyre HJ, Sause WT (1986) Evaluation of the response of unresectable carcinoid tumors to radiotherapy. Int J Radiat Oncol Biol Phys 12: $301-305$

Schmitt A, Bernhardt P, Nilsson O, Ahlman H, Kölby L, Maecke HR, Forssell-Aronsson E (2004) Radiation therapy of small cell lung cancer with 177Lu-DOTA-Tyr3-octreotate in an animal model. J Nucl Med 45: $1542-1548$

Sowby FD (1983) ICRP Publication 38 Radionuclide transformations, p 756. Oxford: Pergamon Press

Valkema R, De Jong M, Bakker WH, Breeman WA, Kooij PP, Lugtenburg PJ, De Jong FH, Christiansen A, Kam BL, De Herder WW, Stridsberg M, Lindemans J, Ensing G, Krenning EP (2002) Phase I study of peptide receptor radionuclide therapy with [In-DTPA] octreotide: the Rotterdam experience. Semin Nucl Med 32: 110-122

Waldherr C, Pless M, Maecke HR, Haldemann A, Mueller-Brand J (2001) The clinical value of [90Y-DOTA]-D-Phe1-Tyr3-octreotide (90Y-DOTATOC) in the treatment of neuroendocrine tumours: a clinical phase II study. Ann Oncol 12: $941-945$

Wängberg B, Westberg G, Tylen U, Tisell L, Jansson S, Nilsson O, Johansson V, Scherstén T, Ahlman H (1996) Survival of patients with disseminated midgut carcinoid tumors after aggressive tumor reduction. World J Surg 20: 892 -899, discussion 899 